\title{
Policy Options to Regulate PV in Low Voltage Grids-Australian Case with International Implications
}

\author{
Glen Currie $^{1}$ (D) $\cdot$ Robin Evans $^{1} \cdot$ Colin Duffield $^{1} \cdot$ Iven Mareels $^{1,2}$ \\ Received: 28 March 2019 / Accepted: 4 June 2019 / Published online: 26 June 2019 \\ (C) Springer Nature Singapore Pte Ltd. 2019
}

\begin{abstract}
This article shows a socio-technical evaluation of the Australian case which has international implications for energy policy and regulation. Australia is one of few places globally that have faced domestic PV (photovoltaic system) adoption of above 50\% of feeder connections. This leads to grid issues and is an emerging issue globally. Grid issues include over-voltage, thermal overload, frequency instability and voltage instability. This paper offers a policy process to regulate PV. This research extends earlier econometric modelling of Australian PV adoption data and extends it to focus on PV regulation in low voltage grids. This paper explores five policy options to help regulate PV in low voltage grids: the role of distribution businesses, inverter regulation, PV export limits, cost reflective pricing, and storage. Policy complexity comes from the need to incorporate many stakeholder perspectives, and this research contributes to policy clarity by seeking a consensus.
\end{abstract}

Keywords Delphi interviews $\cdot$ Energy policy $\cdot$ Energy regulation $\cdot$ Low voltage grids $\cdot$ Photovoltaics

\section{Introduction}

High penetrations of PV in low voltage grids causes voltage rise and can cause thermal overload of cables and transformers and other problems. Clever system design can reduce these problems and offer services to the wider electricity system via frequency control and voltage control.

Governments are struggling to regulate PV because consumers expect free choice to increase PV penetration. Therefore, this research explores policies for regulation of PV that balance the system needs and the consumer needs. The method is expert interview using a Policy Delphi method for analysis [22] and this research could be input for grid planning and energy policy [28].

The problem of regulating PV when the electorate expects free choice to add PV is a wicked problem [36] and can be tamed but not solved. This research can be used to tame PV on low voltage grids and reflects the move from centralised electricity systems to distributed customer end solutions. These

Glen Currie

glen.currie@unimelb.edu.au

1 School of Engineering, The University of Melbourne, Melbourne, Australia

2 Lab Director, IBM Research Australia, Melbourne, Australia customer end solutions take advantage of the huge advance in recent years in communications and computing power [24] and the consequent ability to generate feedback to improve system control [6]. The resulting changed electricity system is called in this paper the "Customer Grid".

\section{Context}

\section{PV in Australia}

PV overvoltage is acutely felt in Australia due to world leading PV market penetration of up to 50\%, long low-voltage-feeders with significant voltage-droop, and high solar insolation. Excessive PV generation in a single feeder can cause a backwards flow of power at the transformer and most Australian transformers are designed for single direction flow. PV systems cutout when voltage rises above the operating range of the PV inverter [4].

Over 1.6 million homes with PV in Australia have registered for a subsidy with the Australian Government. Table 1 shows Australian PV installations by state and by year.

From 2009 to 2012 saw the average domestic PV installation of negative cost to the consumer. This means the subsidy was higher than the price of PV and is marked with a red circle in Fig. 1. The result of this negative cost is reflected in Table 1 
Table 1 The number of domestic PV installation by state/territory in the period 2001-2016

\begin{tabular}{llllllllll}
\hline YEAR & ACT & NSW & NT & QLD & SA & TAS & VIC & WA & NATIONAL \\
\hline $2001-7$ & 102 & 779 & 26 & 475 & 1037 & 26 & 828 & 262 & 3535 \\
2008 & 278 & 2890 & 88 & 3087 & 3456 & 161 & 2036 & 2068 & 14,064 \\
2009 & 803 & 14,008 & 215 & 18,283 & 8569 & 1452 & 11,847 & 11,157 & 66,334 \\
2010 & 2323 & 69,988 & 637 & 48,697 & 16,705 & 1889 & 35,676 & 22,293 \\
2011 & 6860 & 80,272 & 401 & 95,303 & 63,553 & 2475 & 60,214 & 51,667 & 360,745 \\
2012 & 1522 & 53,961 & 513 & 130,252 & 41,851 & 6364 & 66,204 & 42,653 & 343,320 \\
2013 & 2411 & 33,998 & 1024 & 71,197 & 29,187 & 7658 & 33,332 & 21,600 & 200,407 \\
2014 & 1225 & 37,210 & 1026 & 57,748 & 15,166 & 4207 & 40,061 & 23,496 \\
2015 & 1066 & 33,484 & 1197 & 39,510 & 12,084 & 2020 & 31,360 & 20,799 & 180,139 \\
2016 & 999 & 29,796 & 1793 & 35,717 & 12,682 & 2580 & 26,506 & 25,302 \\
TOTAL & 17,619 & 357,438 & 7024 & 501,387 & 205,946 & 28,882 & 308,977 & 221,533 & 135,520 \\
\hline
\end{tabular}

showing PV installations jumped from 66,000 to 360,000 from 2009 to 2011.

Figure 1 shows PV adoption with the blue line, PV system price with the dotted orange line and subsidy with the green line. The dotted line is cost, and the green line is subsidy. The subsidy uses the first year of Feed-in Tariff (FIT) income after the purchase of PV for a weighted average of the other subsidies.

Patterns of PV uptake were modelled by Green_Energy_Trading [14] as having four PV adoption drivers: level of home ownership; suitability of buildings which measured detached and semi-detached dwellings; $\%$ of household income spent on energy; and the level of new home and renovation activity. The last of these was reflecting the market included many builders that offered PV in new home packages.

\section{International Research on PV Overvoltage}

Internationally, the need for PV regulation is occurring where there is a low voltage distribution grid and a high
PV concentration [16]. The US grid design is primarily high voltage, so the problem is in the European style grids, which include Australia. Most research is from a power engineering perspective $[5,17]$.

Power engineering can address overvoltage with grid-reinforcement, storage, reactive power absorption by PV inverters, active transformers, active power curtailment, and demand response [18]. One fertile area is reactive power management which could increase the PV hosting capacity of a distribution line and transformer by more than $20 \%$ [18]. Reactive power could be best absorbed by the first PV systems on a line to minimise the reactive power absorption. To achieve reactive power absorption by PV inverters the inverters need to be oversized. Haque and Wolfs [17] review the research on PV overvoltage methods, and Ali et al. [5] review a topological approach to managing PV overvoltage.

In addition to this power engineering research there is some policy and regulatory research on PV which is outlined in "Literature and Results" section.
Fig. 1 Subsidy and PV system $\$$ A price per watt and PV installation total by year-sourced from Australian Photovoltaic Institute (APVI) and Australian Bureau of Statistics (ABS)

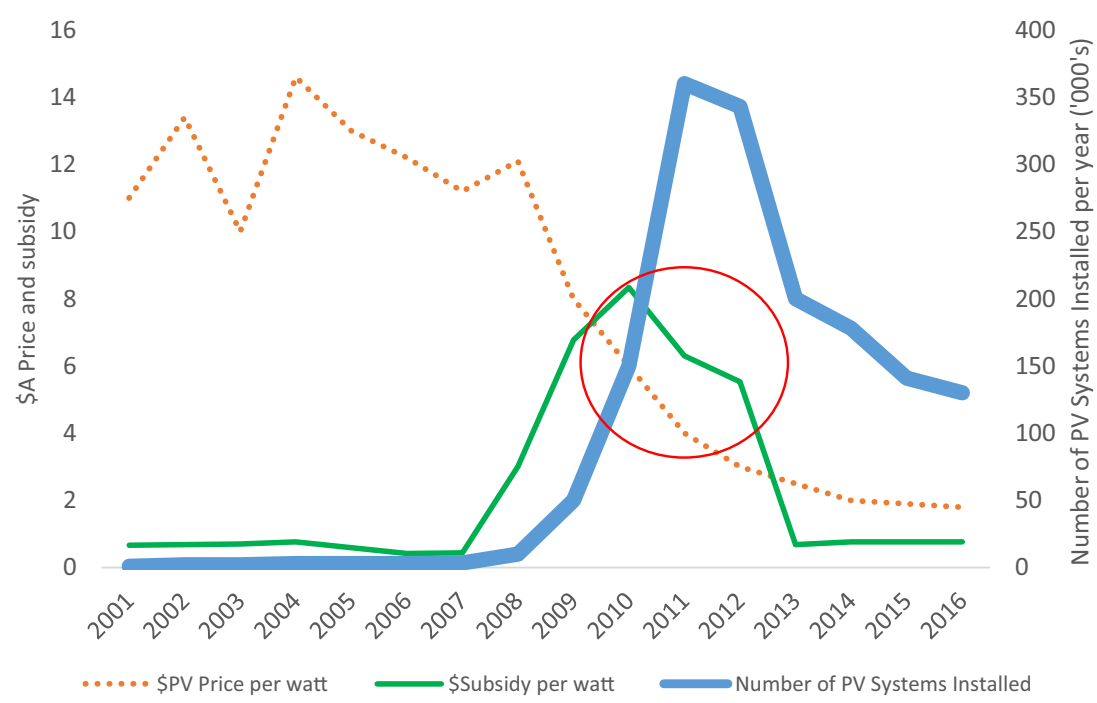




\section{Research Design}

To research regulation of PV in low voltage grids we used the Policy Delphi interview structure [35]. The method was to select 100 energy experts in Australia that had a knowledge of the consumer end of the electricity system. Then the next step was to survey for quantitative and qualitative data. A broad range of stakeholders were interviewed, and the interviews were in-depth with significant open discussion. Fortyone interviews were conducted under University of Melbourne Ethics ID 1851018.1.

The experts who agreed to an interview were emailed a Plain Language Statement and Consent and they confirmed their acceptance of the Consent via email. They were then interviewed face to face or online with a video conferencing software. These interviews were conducted from April 2018 until July 2018, coincidently a time of great turmoil in Australian energy policy. The main effect of this turmoil was that interviewees were keen to share their opinions. Political disagreement about Australian energy policy contributed to the replacement of Australian Prime Minister Malcolm Turnbull with Scott Morrison on the 24th of August 2018.

The interview questions covered the role of distribution businesses, the role of PV export limits, the role of high technology customer inverters, the role of cost reflective pricing and the role of storage. Table 2 shows the questions.

\section{Literature and Results}

The interviews sought views on PV regulation through changing the role of distribution businesses, inverter regulation, PV export limits, cost reflective pricing, and storage. The interviewees included three politicians who had had an energy portfolio and many energy leaders. A cross section of Australian energy specialists were interviewed including people in academia, business, government, policy and not for profit organisations.

\section{The Distribution Businesses (DB) Role in Facilitating this Energy Transition?}

The energy transition will involve DB's as they control the key constrained assets. This change is constrained, as Australian monopoly mean they cannot operate in a competitive market. Australian DB's have tended to leave a lot of market innovation to retailers as this has generally been outside their income stream. This has changed recently in Australia with the establishment of market facing companies that have a Chinese wall between them and their DB owner. Examples include Mondo [25] and Yurika [40].

DB's are facing other drivers of change than PV. These include increasing EV uptake [32], the deterioration of their Return on Assets, the rise of aggregators acting as intermediaries with customer, the customer drive for energy independence and the pressure from government. On the other hand, DB's operate in a highly regulated space, so their response to the Customer Grid will be very conservative. This conservatism is partly due to the high reliability hurdles for distribution businesses who are required to meet reliability hurdles. If they do not meet certain service levels, the asset payment is zero and this has built a deep conservatism in these businesses. Other barriers to change at DB's include entrenched political viewpoints pro or anti renewables. There is also regulatory barrier to change in that Rule 6.1.4 of the National Energy Rules needs to change to allow DB's to price their services on exported power.

Real-time-pricing and fast response technologies to reduce peak load can be created using fast response technologies, smart appliances, energy storage and home energy controllers.

Table 2 Questions used in this research on PV in the electricity system

How likely are we to succeed? 1-low chance 7-certain

\# of years in future $1-10$

This is shown in the graphs below as "Customer Grid" and refers to policy to improve the innovation and customer focus of distribution businesses.

2 The role of $P V$ export limits.

This refers to policy allowing the network to control additional PV on the grid.

3 The role of smart inverters to improve the grid? This is shown in the graphs as "high tech inverters" and refers to inverter functions for voltage control as well as load control.

$4 \quad$ The role of network price reform to improve the grid?

This is shown in the graphs as "cost reflective pricing" and refers to the use of price reform in altering customer energy-related decisions.

5 The role of home battery storage rules.

This is shown in the graphs as "storage playing a key role" and refers to the controls on storage to improve the operation of the grid.
$1-7 \quad 1-10$

$\begin{array}{llc}1-7 & 1-7 & 1-10 \\ 1-7 & 1-7 & 1-10 \\ 1-7 & 1-7 & 1-10 \\ 1-7 & 1-7 & 1-10 \\ 1-7 & 1-7 & 1-10\end{array}$


There has been some network pricing innovation in the Netherlands as shown in Fig. 2. Figure 2 shows a structure that offers consumers a band of maximum PV input and maximum draw on the grid, and a separate and higher tariff for any electricity outside this band. The goal of this Enexis tariff is flattening of load on the distribution system.

The ability of the distribution businesses to work with the data they hold at present, and work towards a sharing of that data to allow others to participate in the solution will take some changes in current DB behaviour and culture. There are some signs of this change beginning. For example, the Victorian government has proposed a data repository of all smart grid data, which may lead to a market emerging. The distribution businesses are highly regulated business, which is incompatible with innovation, so they will not run the market, but they are a key participant as DB's have privileged knowledge about the network.

The COAG Energy Council which is the penultimate political forum for energy policy considered requirements for large wind and large PV generators to offer storage, and fast frequency response in 2017. Smaller systems could technically offer this in the future. The AS4777 standards body is considering fast frequency response in 2019. DB reforms are unlikely before about 2026 as shown on Fig. 6 .

\section{Inverter Regulation}

Air-conditioning, PV systems, storage systems and EV charging all use inverters that could help the grid.

- The first way that inverters can help the grid is through providing reactive power and voltage control and perhaps in the future, frequency control. Inverters can contribute to voltage control with voltage set points that limit output and help protect transformers from reverse current and the problem of overvoltage events [33]. Voltage control built into inverters is coming in an update to the Australian PV inverter standard AS4777. AS4777 already has a droop setting to respond to frequency rise by reducing PV output, and works the other way if there is a battery in the system. In addition to the sustained droop response, AS4777 requires the inverters provide reactive power by PQ capability diagram settings. Our expert interviews recommended the updating of inverter technology though standards which can be led by industry.

- The second way inverters can help the grid is by automatically responding to network conditions through battery storage of PV, load reduction or load switching. Distribution businesses generally are not sure how to manage this disaggregated resource and it is not yet clear what settings are best for the grid.

- Voltage control built into inverters can also help homeowners receive more real power, and less apparent power may offer a power saving of up to $2.5 \%$ and increase the life of household devices from an average of nine years, to an average of 12 years [12].

To regulate inverters, a challenging task is getting agreement on standards and appropriate regulation. Some futureproofing is possible if new inverters are programmable and compatible with the network. Regulation can ensure we install grid friendly inverters. Australia is ready for such a transition [26]. The most recent demonstration of readiness is outlined in the Finkel Review [13].

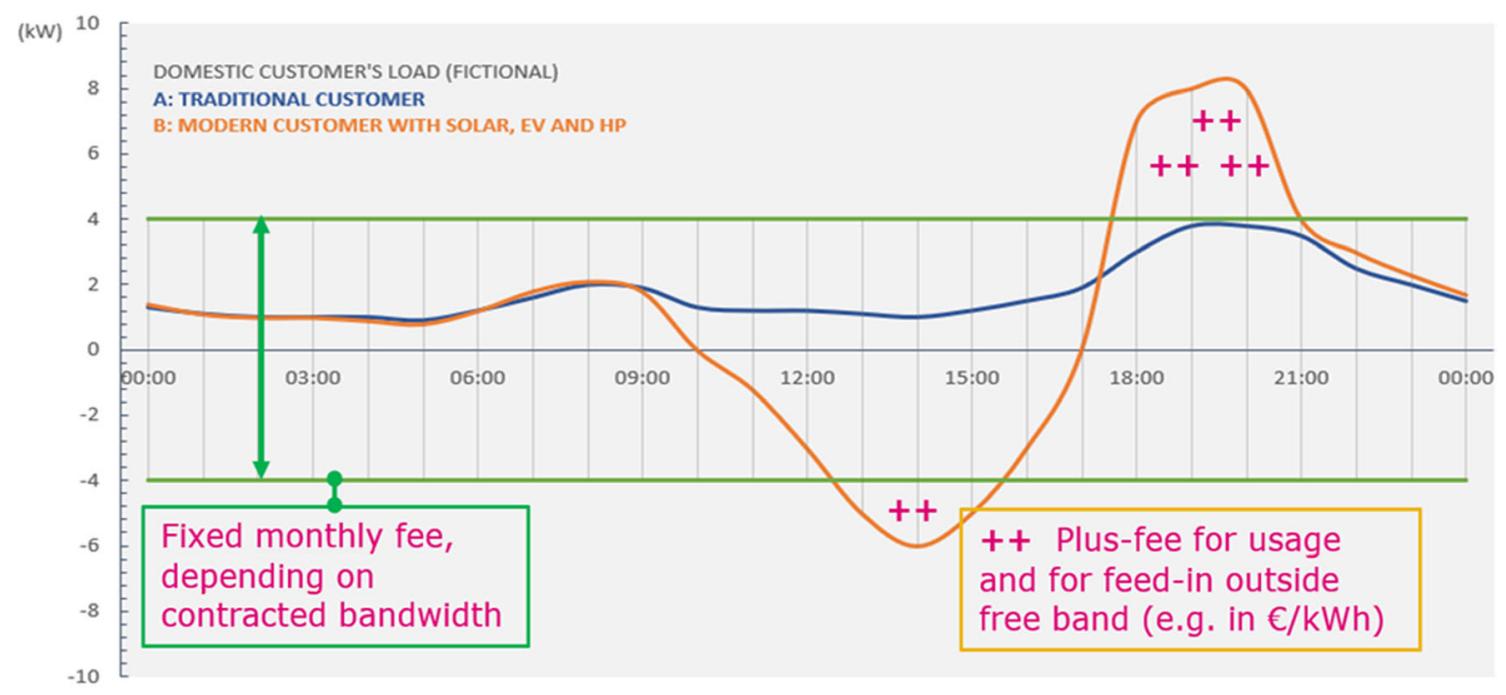

Fig. 2 Symmetrical Band Model Network Tariffs (Enexis Holding Netherlands) 


\section{PV Export Limits}

Grid export limits are being used in Germany and Australia in 2019. They are used in cases of high penetration of PV on distribution networks. Australian DBs impose PV export limits usually at a fixed level of $4.8 \mathrm{kw}$. Instead of PV export limits, dynamic control of inverters can be used. PV overvoltage is dynamic, so PV export limits and controls on customer assets should be dynamic [33].

The expert interviews showed a concern that PV export limits was a DB centric solution that does not meet other goals of environment and community drive for control of their electricity system. They were concerned that PV export limits are a short-term fix that will be needed less as the grid technology develops. Long term we do not want the distribution businesses to refuse connections or limit exports in built up areas but can expect this is a tool in dispersed grids.

PV ramp rate may also need regulating in high PV density areas. A potent tool for managing ramp rate is storage which is discussed in "Storage" section.

\section{Cost Reflective Pricing}

Cost reflective pricing includes all actual costs of delivering electricity. When people generate PV power their current fees for network services (for the times they need the grid) are not paying the network costs [30]. This is an increasing problem and requires policy changes to deliver economic return to the network owners.

Variable network pricing has polled as being unpopular with customers, but it is a key tool to reduce electricity prices. Regulations allow network companies implement cost reflective pricing, but they have been slow to adopt this. The pairing of certain load profiles with network tariffs would give customers the signal for investment in their energy devices. This should reward people for reducing large and sudden changes in generation or load, reward self-consumption of renewable energy to use the network less, and reward peer-to-peer storage services that only use the local grid.

Internationally there are capacity markets. Germany is one example where Sonnen Batteries trades in their capacity market and offers a 15-year PPA to retail customers. It is through these market innovations that actual cost reflective pricing can be made attractive to customers.

Any change to cost reflective network pricing would need to be automatic to avoid increasing the complexity of the current system. Customer pricing would need to reflect lower costs for the feeders that are not under constraint. This would allow the retailer to sort out their efficient operation and leave the focus on the constrained feeders. Capacity pricing using a KvA basis is being tested with commercial customers in Queensland [11].
Spatially different pricing is unlikely as regional residents would pay a far higher network charge. On the other hand, temporal network pricing is possible. One example is DMIS run by AEMO in Australia [3] which is a government led tender that encouraged market solutions. The outcome has included a distributor (CitiPower Powercor) dropping the system voltage for a period and a retailer (Powershop) working with retail customers to offer $\$ 10$ per successful curtailment.

To achieve optimisation of the distribution network, the network pricing needs to be dynamic. Virtual net metering might help as this two-way flow could better recognise distributed energy resources (DER). Outcomes might include optimised distribution grid capital decisions, optimised regulation as more information is available, smart charging of electric vehicles (EV), and better decisions on consumer purchase and consumer use of technology such as air-conditioning, and PV.

\section{Storage}

Storage can reduce grid issues $[21,33]$. It offers a solution to the intermittency problems of renewables, can smooth peaks, offer fast frequency response, and load shift. This means that distribution businesses can smooth power, manage peaks and regulate frequency.

The world's largest lithium-ion battery was commissioned in 2018 at Hornsdale in South Australia and it participates profitably in the ancillary markets [8]. This is further enabled by the associated windfarm. A sample of exports are shown in Fig. 3.

The levelised cost of grid electricity versus storage and PV is coming close to competitive [20,23]. In Australia, PV and battery packages are being marketed to households with a 7year payback (with the $30 \%$ carbon subsidy on PV). Australian consumers of PV have previously responded to a 7-year payback. There are 24,000 batteries in Australia which is expected to rise to 700,000 by 2027 so appropriate regulation of these will be critical to ensure an optimisation of the electricity system. The may include battery sharing [19]. Customers are likely to accept impositions on their storage if they receive a price benefit [29].

Storage is a key part of the current Virtual Power Plant (VPP) test by the DB United Energy and the company GreenSync [15]. Also a King Island test successfully automated despatch of storage [7].

\section{Quantitative Results}

A summary of the interviews is shown in Figs. 4, 5 and 6. Figure 4 shows how interviewees rate the importance of each of these policy areas. Box and whisker charts show the mean with an X, and 50\% of answers in the box. The outliers show with a dot. 
Hornsdale 100MW Battery in SA (as at 21st May 2019, 13:06 UTC+10)

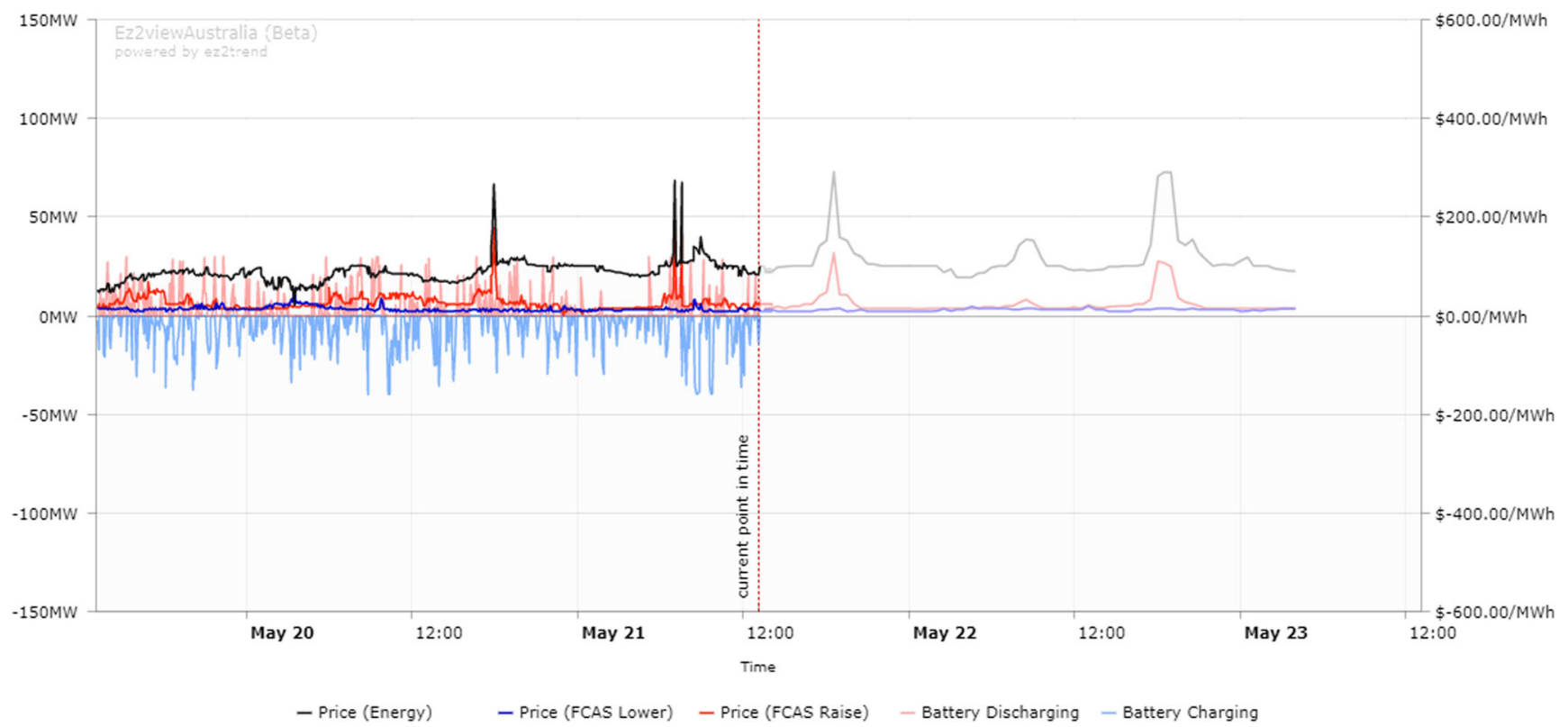

Fig. 3 Hornsdale 100 MW Battery sales and forecast as at midday 21 May 2019

The Australian energy experts rated more highly:

- the engagement of distribution businesses in this change, and

- the need for cost reflective pricing.

The experts agreed we should implement pricing incentives to encourage consumer behaviour in certain directions, but the experts are not keen to see radical pricing reform due to the lack of technical, political, and social support.

Next the likelihood of policies being adopted is shown in Fig. 5.

Fig. 4 Survey of 41 Australian energy experts, results for Importance

\section{IMPORTANCE 1-7 SCALE WITH 7 HIGHEST}

- PV export limits,

- high technology inverters and

- storage.

However, they showed notably lower confidence that distribution businesses would adopt the Customer Grid and a lower confidence with cost reflective pricing.
IMPORTANCE OF

CUSTOMER GRID

IMPORTANCE OF PV EXPORT LIMITS

IMPORTANCE OF HIGH

TECH CUSTOMER

INVERTERS PLAYING A

KEY ROLE

IMPORTANCE OF COST

REFLECTIVE PRICING

IMPORTANCE OF

STORAGE PLAYING A KEY ROLE

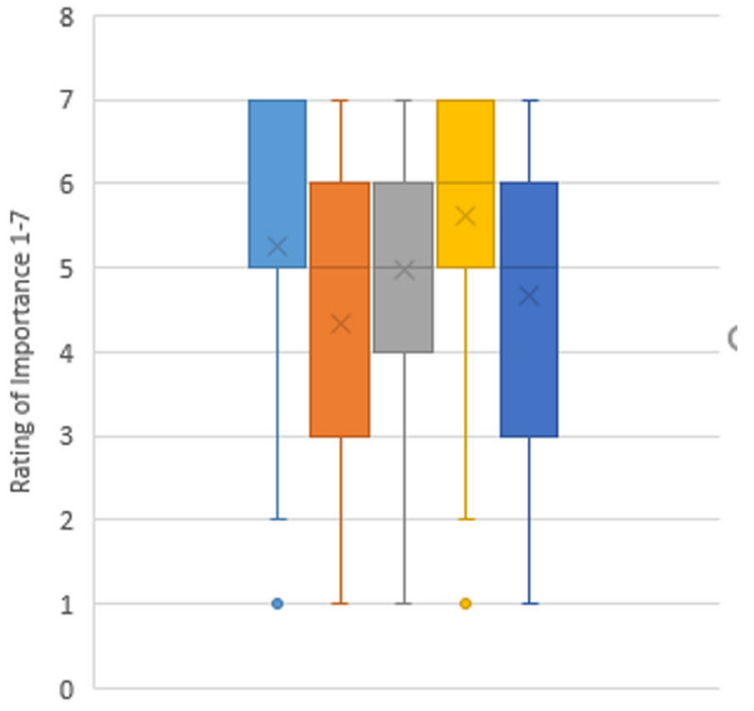


Fig. 5 Survey of 41 Australian energy experts, results for Likelihood of Success
LIKELIHOOD 1-7 SCALE WITH 7 HIGHEST

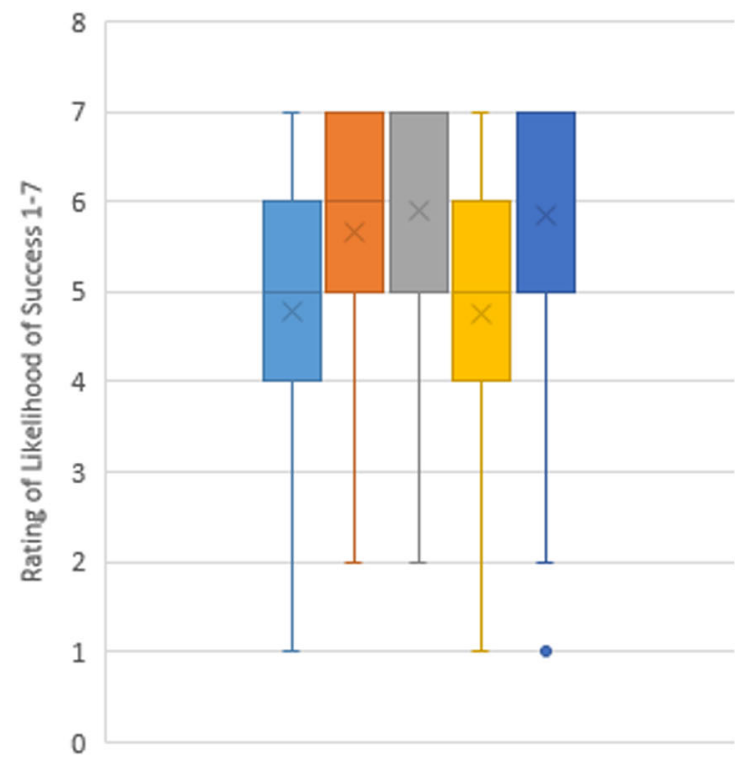

The interviews were in 2018 and asked how many years in the future the policies would begin to be effective. The option offered was a range of 1-10 years and results show in Fig. 6.

These surveys show a caution about the active role of distribution businesses. They see storage as being 3-4 years away and cost reflective pricing as being 4-6 years away. They also see PV export limits and high technology inverters as being available for immediate rollout in the coming 2 years.

\section{Discussion}

The five policy areas explored in this research could regulate PV as shown in Table 3.

To overcome issues from PV, distribution businesses can install expensive equipment such as onload tap changers (OLTC), mechanical voltage regulators, power electronic voltage regulators, STATCOMS, transformer upgrades and line drop compensators (LDC's). The expense of these can drive up the costs of electricity [4]. An alternative solution lies with inverters, which could reduce their negative impact on the grid by autonomously monitoring voltage and setting output voltage with a learning algorithm [38]. Options for inverter control defined in an NREL report [34] include, connect and disconnect, adjustable peak generation, adjustable power factor, Volt-VAR mode to adjust reactive power, frequency ride-through and voltage ride-through to set voltage parameters governing inverter connection shutoff.

These inverter control options offer a capability to manage PV overvoltage by PV output curtailment or the redirection of PV output to storage. Their reactive power capability is important when reactive power control can help manage voltage (particularly on longer feeders.) To do this we would need to
Fig. 6 Survey of 41 Australian energy experts, results for Years in the Future before the policy is implemented

\section{YEARS IN THE FUTURE}

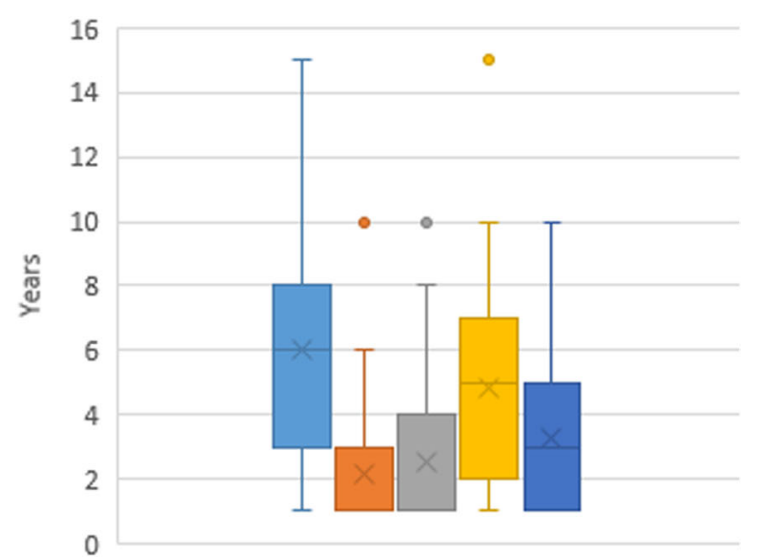


Table 3 How the five policy options might regulate PV

The role of Distribution Businesses $\begin{array}{r}\text { As the manager or owner of the affected assets, facing excessive costs } \\ \text { for asset upgrade they are highly motivated to act to regulate PV using } \\ \text { all tools at their disposal. } \\ \text { The inverter design is controlled by standards and is an excellent way } \\ \text { to regulate PV. } \\ \text { Export limits offer suitable remedy for PV overvoltage in some } \\ \text { circumstances but should be a temporary measure. } \\ \text { Inverter regulations } \\ \text { The incentivising of all stakeholders would be theoretically efficient, } \\ \text { but a fully cost reflective price will not be politically attractive thus } \\ \text { weakening this as a valuable policy focus. } \\ \text { The potent step in overcoming issues from PV will be the integration } \\ \text { of storage. Pricing signals can be used to control the storage settings, } \\ \text { as well as storage inverter regulation, and network regulations. }\end{array}$
Storage

consider changes to the role of distribution businesses, inverter regulation, cost reflective pricing, and storage.

Policy development and regulation of storage is beginning. The Australian Government agency AEMO is developing a register for batteries in Australia [2]. There is a current rollout of 30,000 batteries in South Australia, which should motivate more regulation and policy development. Battery sharing is getting extensive academic interest, including a recent article in Nature Energy [19], and storage is a key part of the current Virtual Power Plant (VPP) test by the DB United Energy and the company GreenSync [15]). The Australian Government supported the King Island test [7] which has also successfully automated despatch of storage. The orchestration of storage to improve grid stability is technically possible. Customers may accept controls on their household batteries, if the energy plan rewards them for this imposition [29].

Sensors and AI are playing an increasing role in grid management. One method of optimising operations is through appliance-level load-control, and appliance tracking using energy signatures. This has no need for plug level hardware. In another application, the use of a simple temperature sensor attached to the outside of the nearest transformer could warn of overload. The capacity price could reward the user for amelioration at times of overload through battery storage of PV, load reduction or load switching. Technology can automatically respond to network conditions, and the main reason that it is not common is that network operators are not sure how to manage this disaggregated resource and it is not yet clear what smart inverter settings are best for the grid.

Information delivered to electricity customers will allow customers to alter the way they use technology such as electric vehicles, to save electricity costs. For example: smartcharging of an Electric Vehicle could save Australians over $\$ 1000$ per year [1]. Additional information can motivate customers and give them control over their electricity and allow them to sell power or sell demand response. Customers will see the grid as more reliable and offering more value if they have information [9]. This increase in information will also help people manage their electricity related buying and electricity use choices.

\section{Conclusion}

Our expert interviews suggest the five policy options to reduce PV overvoltage include changes at the distribution businesses, inverter regulation, PV export limits, cost reflective pricing, and the implementation of more storage. The changes the experts recommend at distribution businesses are encouraging innovation and capacity markets. These markets will allow users to have choice in their grid access, and higher levels of network service will cost more. A scheme for this is outlined in [10] paper "A Market Mechanism for Electric Vehicle Charging Under Network Constraints.” [10]. This will be enabled with the availability of smart meter data and the controllability of customer inverters. Our expert group suggested the technology for inverters to manage PV overvoltage is too uncertain for fixed regulation, but there is an option for open architecture in the inverter programming that will allow future proofing. Our interviews showed there is comfort that the standards process will provide adequate guidance without a push from government.

Electricity systems around the world are struggling to remain reliable, cheap and clean [37].

- Reliable: The overvoltage from PV, and the undervoltage from air-conditioning and other loads is making low voltage grids less reliable, and the peakiness and high renewables penetration is making frequency control of the whole grid less reliable. There is an opportunity to increase reliability of the low voltage electricity system via regulations that will to deliver reliability.

- Step 1 is to build strong regulatory controls on the inclusion of controlled storage in homes that want to add PV.

- Step 2 is control of loads such as air-conditioning is seen as the second key step to increase reliability [31] 
- Cheap: The electricity system was designed to meet peaks with ample spare capacity, but the peak load has increased at a time that the total electrical sales have reduced, so less electricity is sold but in peakier bursts driving up costs. Our expert interviews suggest that a balance between government regulation and private industry is the path forward.

- Step 1 is that governments free up trade and data flow, we expect this data to allow an optimisation of the system. Customers should then see equitable pricing of low-voltage electricity distribution tariffs, which send signals to the market to drive better decisions on purchase of distributed energy sources such as $\mathrm{PV}$, and purchase of energy for large loads such as electric vehicle charging [39].

- Step 2 is to encourage new markets including secondary markets with brokers, integrators, aggregators, new goods, and new services. These markets would support competition, which should drive prices down. An intervention the interviewees do not support is cost reflective pricing. The change to dynamic pricing is surprisingly low on their priority. This change is seen as autocratic and it is perceived that it will take too long. The view is that we will be better to use a distribution service market to set pricing. There is a rich literature on tariffs that should mean that market settings for equitable sharing of costs and driving lower system costs can be effectively designed. Customers will respond if they see a benefit [27].

- Clean: The supply side of the electricity system is also becoming more difficult to control as renewable energy is integrated (wind and PV fluctuate with the weather). One option is to build more infrastructure to meet contingencies, but this drives up electricity costs.

- Step 1 is to regulate PV to allow wide adoption rather than widespread use of PV export limits. Our expert interviewees see these as a powerful short-term tool for managing overload on certain feeders but not in the long-term.

This research offers a medium-term view of suitable regulation of PV in low voltage grids and can contribute to the development of policies.

Acknowledgements This research received grants from the University of Melbourne and through the class of 1948 scholarship Sir Louis Matheson Prize, 2018.

\section{References}

1. AEMC (2014) Residential Electricity Price Trends. (Reference: EPR0040). Sydney: Australian Government Retrieved from https://www.aemc.gov.au/markets-reviews-advice/2014residential-electricity-price-trends
2. AEMC (2018) 2018 Retail Energy Competition Review, Final Report, 15 June 2018. (RPR0007). Sydney: Australian Government Retrieved from https://www.aemc.gov.au/sites/ default/files/2018-06/Final\%20Report.pdf Retrieved on January 11,2019

3. AEMO (2017) Aemo and arena demand response trial to provide 200 megawatts of emergency reserves for extreme peaks. Retrieved from https://www.aemo.com.au/Media-Centre/ AEMO-and-ARENA-demand-response-trial-to-provide200MW-of-emergency-reserves-for-extreme-peaks Retrieved on October 11, 2017

4. Alexander D, Wyndham J, James G, McIntosh L (2017) Networks Renewed: Technical Analysis. Retrieved from Sydney, Australia: https://www.uts.edu.au/sites/default/files/ NetworksRenewedTechnicalAnalysis.pdf Retrieved on January 11, 2019

5. Ali MS, Haque MM, Wolfs P (2019) A review of topological ordering based voltage rise mitigation methods for lv distribution networks with high levels of photovoltaic penetration. Renewable and Sustainable Energy Reviews, Elsevier, Amsterdam (Netherlands), 103, 463-476

6. Arampatzis T, Lygeros J, Manesis S (2005) A Survey of Applications of Wireless Sensors and Wireless Sensor Networks. Paper presented at the Proceedings of the 2005 Mediterrean Conference on Control and Automation Intelligent Control Limassol (Cyprus)

7. ARENA (2018) King Island Energy Integration Project. Retrieved from https://arena.gov.au/projects/king-island-renewable-energyintegration-project/ Retrieved on 21 June 2018

8. Browne N, Pokharel B (2018) South Australia's power sector: renewables, batteries and the future role of gas. The APPEA Journal 58(2):505-507

9. Buchanan K, Russo R, Anderson B (2015) The question of energy reduction: the problem(S) with feedback. Energy Policy 77:89-96. https://doi.org/10.1016/j.enpol.2014.12.008

10. de Hoog J, Alpcan T, Brazil M, Thomas DA, \& Mareels I (2016) A market mechanism for electric vehicle charging under network constraints. IEEE Transactions on Smart Grid, IEEE, New York (United States), 7(2), 827-836

11. Energex (2018) Network tariff guide. Retrieved from Brisbane:

12. Faruqui A, Arritt K, Sergici S (2017) The impact of Ami-enabled conservation voltage reduction on energy consumption and peak demand. Electr J 30(2):60-65

13. Finkel A, Moses K, Munro C, Effeney T, OKane M (2017) Independent Review into the Future Security of the National Electricity Market: Blueprint for the Future. Canberra: Australian Government Retrieved from http://www.environment.gov.au/ energy/publications/electricity-market-final-report Retrieved on January 11, 2019

14. Green_Energy_Trading (2014) Postcode and Income Distribution of Solar. REC Agents Report. Retrieved from http://www.recagents. asn.au/wp-content/uploads/2014/04/GET-Postcode-report-forRAA-April-2014.pdf Retrieved on 1 February 2019

15. GreenSync (2017) Community grid projects. Retrieved from https:/greensync.com/projects/community-grid-project/ Retrieved on 1 September 2018

16. Guangya Y, Marra F, Juamperez M, Kjaer SB, Hashemi S, Østergaard J, ... Frederiksen KH (2015) Voltage rise mitigation for solar Pv integration at lv grids. Journal of Modern Power Systems and Clean Energy, Springer, New York (United States), 3(3), 411-421

17. Haque MM, Wolfs P (2016) A review of high Pv penetrations in lv distribution networks: present status, impacts and mitigation measures. Renewable and Sustainable Energy Reviews, Elsevier, Amsterdam (Netherlands), 62, 1195-1208 
18. Hashemi S, Østergaard J (2016) Methods and strategies for overvoltage prevention in low voltage distribution systems with Pv. IET Renewable Power Generation, London (United Kingdom), 11(2), 205-214

19. Kittner N, Lill F, Kammen DM (2017) Energy storage deployment and innovation for the clean energy transition. Nat Energy, (United Kingdom 2:17125. https://doi.org/10.1038/nenergy.2017.125

20. Lai CS, McCulloch MD (2017) Levelized cost of Electricity for Solar Photovoltaic and Electrical Energy Storage. Applied Energy, Elsevier, Amsterdam (Netherlands), 190, 191-203

21. Liu C-C, McArthur S, Lee S-J (2016) Smart Grid Handbook, 3 Volume Set (Vol. 1). New Jersey (United States): John Wiley \& Sons

22. McGeoch M, Brunetto Y, Brown K (2014) The policy Delphi method: contribution to policy and strategy within energy Organisations: a 2013 Malaysian case study with global implications. Quality \& Quantity, International Journal of Methodology, Springer, Amsterdam (Netherlands), 48(6), 3195-3208

23. Mohammadi F (2018) Electric Vehicle Battery Market Analysis: Lithium-Ion. Paper presented at the Proceedings of the First International Conference on Modern Approaches in Engineering Sciences Tbilisi (Georgia)

24. Mohideen R, Evans R (2015) Shaping our technological futures. IEEE Technol Soc Mag, IEEE New York (United States) 34(4):83-86

25. Mondo (2019) Mondo company website. Retrieved from https:// mondo.com.au Retrieved on 21 May 2019

26. Nelson T (2016) Redesigning a 20th Century Regulatory Framework to Deliver 21st Century Energy Technology. Journal of Bioeconomics, Editor Springer, New York (United States), 1-18

27. Ocha N (2016) Embracing an Adapable and Flexible Posture. IEEE Energy and Power, Editor IEEE, New York (United States)

28. Ochoa LF, Mancarella P (2012) Low-Carbon Lv Networks: Challenges for Planning and Operation. Paper presented at the 2012 IEEE Power and Energy Society General Meeting, San Diego (United States)

29. Ochoa LN, Pilo F, Keane A, Cuffe P, Pisano G (2016) Embracing an adaptable, flexible posture: ensuring that future European distribution networks are ready for more active roles. IEEE Power and Energy Magazine, IEEE New York (United States) 14(5):16-28. https://doi.org/10.1109/MPE.2016.2579478

30. Passey R, Haghdadi N, Bruce A, MacGill I (2017) Designing more cost reflective electricity network tariffs with demand charges. Energy Policy, Elsevier, Amsterdam (Netherlands), 109, 642-649

31. Passey R, Watt M, Bruce A, MacGill I (2018) Who pays, who benefits? The financial impacts of solar photovoltaic systems and air-conditioners on Australian households. Energy Research \& Social Science, Elsevier (Netherlands), 39, 198-215

32. Petrou K, Quiros-Tortos J, Ochoa LF (2015) Controlling electric vehicle charging points for congestion Management of Uk lv Networks. Paper presented at the 2015 IEEE Power \& Energy Society Innovative Smart Grid Technologies Conference (ISGT), Washington

33. Procopiou AT, Petrou K, Ochoa LF, Langstaff T, Theunissen J (2018) Adaptive Decentralized Control of Residential Storage in Pv-Rich Mv-Lv Networks. IEEE Transactions on Power Systems, IEEE New York (United States)

34. Reiter E, Ardani K, Margolis R, Edge R (2015) Industry Perspectives on Advanced Inverters for Us Solar Photovoltaic Systems. Grid Benefits, Deployment Challenges, and Emerging Solutions (NREL/TP-7A40-65063). Retrieved from Golden, CO (United States): https:/www.nrel.gov/docs/fy15osti/65063.pdf

35. Turoff M (1970) The Design of a Policy Delphi. Technological forecasting and social change, Elsevier, New York (United States), 2(2), 149-171

36. West C (1967) Guest editorial: wicked problems. Management Science, Published by Institute for Operations Research and the Management Sciences, Catonsville, MD (United States), 14(4), $141-142$

37. Wyman O (2016) World energy trilemma 2016. Retrieved from London (United Kingdom):

38. Xia L (2016) Distributed Demand Side Management and Tariff Design in Distribution Networks. (PhD), University of Melbourne, Australia

39. Xia L, Mareels I, Alpcan T, Brazil M, Hoog JD, Thomas DA (2014) A Distributed Electric Vehicle Charging Management Algorithm Using Only Local Measurements. Paper presented at the ISGT 2014, Washington

40. Yurika (2019) Yurika company website. Retrieved from https:// www.yurika.com.au/ Retrieved on 21 May 2019

Publisher's Note Springer Nature remains neutral with regard to jurisdictional claims in published maps and institutional affiliations. 